\title{
O ENSINO DE CIÊNCIAS E A FORMAÇÃO DE PROFESSORES DO ENSINO FUNDAMENTAL NO CURSO DE PEDAGOGIA.
}

\author{
Anderson Clay Rodrigues ${ }^{\mathrm{a}}$ \\ Cleusa Suzana Oliveira de Araujo ${ }^{\mathbf{b}}$
}

A R T I C L E I N F O

Palavras chave:

Ensino de Ciências;

Formação de professores;

Pedagogia

E-mail:

a anderson_clay@hotmail.com

bcleusasuzanaaraujo@gmail.com.

\section{R E S U M O}

Este artigo apresenta o levantamento de registros do acompanhamento dos acadêmicos do $7^{\circ}$ período do curso de Pedagogia, da Universidade do Estado do Amazonas UEA, durante o Estágio Docência do Ensino Superior, com carga horária de $60 \mathrm{~h}$, requisito do Regimento Interno do Curso de Mestrado Acadêmico Educação em Ciências na Amazônia, capítulo VII, Seção III, do PPGEEC/UEA. O período observado da disciplina Ciências da Natureza na Educação Infantil e Anos Iniciais do Ensino Fundamental subsidiou a coleta de dados para elaboração deste documento. Dos desdobramentos, discussão e reflexão analítica das questões mediadas pela disciplina abordaremos os principais elementos do processo formativo. A partir das observações no desenvolvimento das aulas e a aplicação do questionário nos pautaremos no referencial teórico para as análises dos resultados. Assim, registramos que o período de envolvimento com o acompanhamento dos acadêmicos do curso de Pedagogia nos possibilitou refletir sobre o conhecimento adquirido no período de investigação e, aos poucos, tomar consciência da necessidade de ressignificação do que se construiu como pesquisador no percurso investigativo Por fim, concluímos que, o processo de transformação da realidade educacional começa prioritariamente, na perspectiva de que ela pode acontecer e o ponto de partida é a formação de professores. Além disso, as mudanças desencadeadas nesse processo se efetivam na medida em que haja a experimentação do movimento açãoreflexão-ação-reflexão.

\section{INTRODUÇÃO}

A formação de professores é um desafio para as instituições de ensino superior devido a crescente necessidade de qualidade profissional numa sociedade em transformação. Demo, 2010 (p. 209) "identifica como problema estrutural a formação docente e discente, o que sinaliza para a necessidade de refazer, ou melhor, conforme o autor, refundar a formação docente nos cursos de Pedagogia”. Nossa abordagem gira em torno dessa preocupação, sendo 
importante considerar dois aspectos fundamentais neste processo: pensar na mudança e propor inovação.

Na contemporaneidade, é essencial que o professor possua uma visão ampla para subsidiar o aluno com conhecimentos no campo científico, conforme Cachapuz (2004, p. 371) define "a ciência é parte inseparável de todas os outros componentes que caracterizam a cultura humana tendo, portanto, implicações tanto nas relações Homem-Natureza como nas relações Homem-Homem". Mais do que nunca, a Ciência é entendida como uma área dinâmica feita para suprir as necessidades humanas em harmonia com a natureza.

Isto posto, nosso trabalho apresenta o levantamento de registros do acompanhamento dos acadêmicos do $7^{\circ}$ período do curso de Pedagogia, da Universidade do Estado do Amazonas - UEA, durante o Estágio Docência do Ensino Superior, com carga horária de 60h, requisito do Regimento Interno do Curso de Mestrado Acadêmico Educação em Ciências na Amazônia, capítulo VII, Seção III, do PPGEEC/UEA. O período observado da disciplina Ciências da Natureza na Educação Infantil e Anos Iniciais do Ensino Fundamental subsidiou a coleta de dados para elaboração deste documento.

\section{METODOLOGIA}

Este trabalho trata-se da elaboração de um texto descritivo construído no âmbito do contexto acadêmico da disciplina Ciências da Natureza na Educação Infantil e anos iniciais do Ensino Fundamental. A base metodológica tem características da pesquisa de levantamento de dados, segundo Gil (2002, p. 51) define:

As pesquisas deste tipo caracterizam-se pela interrogação direta das pessoas cujo comportamento se deseja conhecer. Basicamente, procede-se à solicitação de informações a um grupo significativo de pessoas acerca do problema estudado para, em seguida, mediante análise quantitativa, obterem-se as conclusões correspondentes aos dados coletados.

O contexto do levantamento dos dados ocorreu numa turma de Pedagogia de $7^{\circ}$ período da Escola Normal Superior - ENS/UEA, sendo 21 acadêmicos sujeitos da pesquisa, 


\section{REVISTA REAMEC}

Revista ta Rete Amazônica de Edurecrąio

em Ciências e Matemática
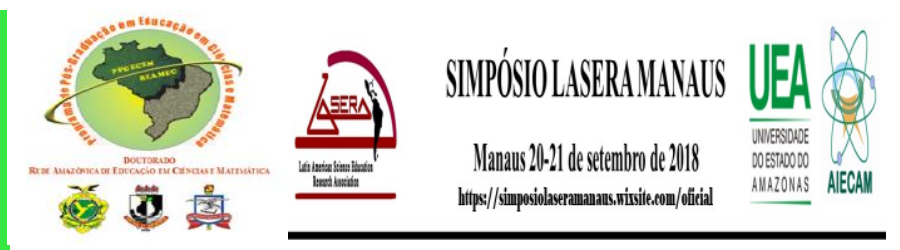

com organização da professora regente do processo de sondagem ${ }^{1}$. Para tanto, buscamos adentrar ao universo desses sujeitos para coleta de informações que contribuíram para a quantificação dos dados obtidos mediante levantamento que podem ser agrupados em tabelas, possibilitando sua análise estatística. Para Gil (2002), as variáveis em estudo podem ser quantificadas, permitindo o uso de correlações e outros procedimentos estatísticos. À medida que os levantamentos se valem de amostras probabilísticas, torna-se possível até mesmo conhecer a margem de erro dos resultados obtidos.

Para a coleta de dados utilizamos os instrumentos como o caderno campo para registros da observação in lócus e aplicamos o questionário, que de acordo com Lakatos e Maconi (2007, p. 111) o “questionário é constituído por uma série de perguntas que devem ser respondidas por escrito". O instrumento foi composto por 7 questões, sendo 2 subjetivas e 5 objetivas com a intenção de registrar as lembranças e experiências das aulas de ciências, do desempenho nas avaliações de ciências, do ensino dos professores de ciências e a proposta de formação concebida pelos acadêmicos em relação estratégias/metodologias de ensino de seus professores há época de estudos na escola de educação básica, além da expectativa da disciplina no decorrer do curso.

Sendo assim, com o uso de todos esses instrumentos próprio da pesquisa, fizemos esta conexão a partir da realidade acadêmica, para construção da base de análise da formação de professores na disciplina de Ciências no universo da academia.

\section{RESULTADOS E DISCUSSÃO}

\subsection{Levantamento de dados e discussão dos resultados obtidos de sondagem aplicada aos acadêmicos do curso de Pedagogia}

Nossa imersão na realidade dos sujeitos proporcionou o desenvolvimento do trabalho com o envolvimento de 21 acadêmicos que corresponderam com a devolutiva de forma positiva dando suas contribuições com $100 \%$ dos participantes, como demonstramos no gráfico 01:

Revista REAMEC, Cuiabá - MT, V. 6, n. Especial, dez 2018, ISSN: 2318-6674 


\section{REVISTA REAMEC}

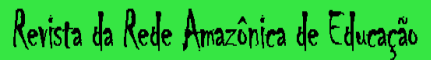

em Ciências e Matemática
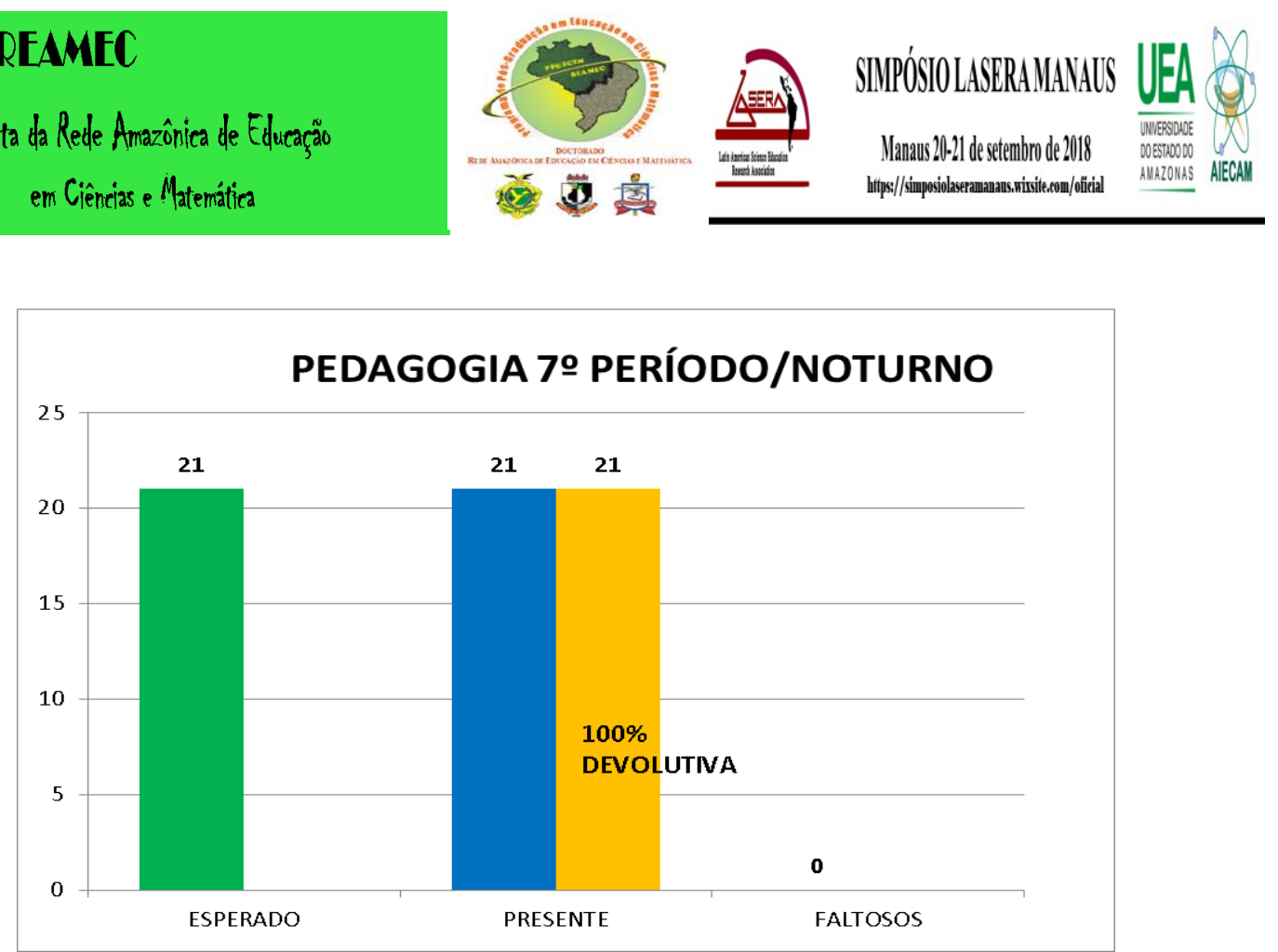

Fonte: Rodrigues (2018)

$\mathrm{Na} \mathbf{1}^{\mathrm{a}}$ pergunta do questionário tabulamos os dados das questões relacionadas com as lembranças dos acadêmicos sobre as aulas de Ciências enquanto alunos do Ensino Fundamental, com seus respectivos resultados. A partir de uma análise realizada das respostas revelaram uma indicação de frustração no processo educacional devido a ausência de dinamismo nas aulas de Ciências culpabilizando a atuação do professor. Embasados nestas informações, é possível observar que na questão 1 obtivemos os quantitativos com os respectivos percentuais: 10 (dez) alunos recordam somente Dos conteúdos com um percentual de 48\%; 2 (dois) alunos, sendo o percentual de 10\% no universo pesquisado registraram que marcou em sua trajetória escolar o Processo de leitura e as Aulas interessantes ministradas pelo professor da disciplina; 1 (um) aluno em cada análise, de um percentual de 5\% em cada sinalizaram que lembram do trabalho do professor com o Livro didático, Dos conceitos abstratos, Da horta escolar e Do estímulo à leitura. Do total, observamos outras lembranças que revelam o percentual de $15 \%$. Nesse cenário, recorremos a Santos $(2012$, p. 16) quando afirma que "o professor é aquele que organiza o processo de ensino, que constrói sínteses e aceita os desafios propostos pela prática social”. Estas considerações levam em conta o quanto é essencial o envolvimento dos alunos no processo de ensino-aprendizagem pelo professor tornando-o dinâmico e conectado com a realidade dos sujeitos inseridos nesse contexto escolar.

Os resultados de cada uma das questões trazidas para a reflexão da formação de professores referem-se ao olhar do aluno de suas experiências vividas em diversos períodos de 


\section{REVISTA REAMEC}

Revista da Rede Amazônica de Eduração

em Ciências e Matemática
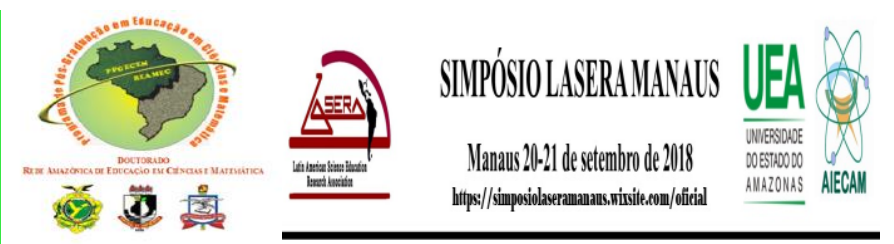

sua vida. A $2^{\mathbf{a}}$ questão trata de como era o desempenho nas avaliações. Este processo de avaliação como afirma Luckesi (2013) afirma que é importante para promover o exercício de práticas na escola que auxilia o professor na tomada de decisão sobre seu trabalho, pois reflete a análise qualitativa e dependendo da escola que oferece o ensino, reflete os resultados da avaliação externa. Portanto, no gráfico 02 abaixo temos o desempenho dos alunos nas avaliações considerando os conceitos bom, razoável, ruim e outros, conforme segue:

\section{Desempenho nas avaliações}

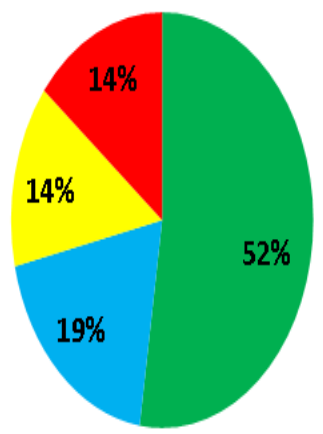

Bom

- Razoável

Ruim

- Outros

Fonte: Rodrigues (2018)

Das informações contidas no gráfico acima percebemos que de modo geral os acadêmicos revelam desempenho mediano, com um percentual de 52\%, com conceito "Bom". É vísivel que havia esforço para apresentar resultados diferentes, contudo, os elementos que dificultavam o avanço está relacionado principalmente pela metodologia/didática que os professores adotavam em sala de aula. Os demais apresentaram percentual abaixo do desempenho previsto, (19\%) sendo "razoável" e (14\%) para os conceitos "ruim/outros aspectos".

\subsection{O professor e o ensino de Ciências}

Sobre a atuação do professor, verificamos no gráfico 03: 


\section{REVISTA REAMEC}

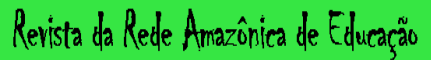

em Ciênniass e Matemática

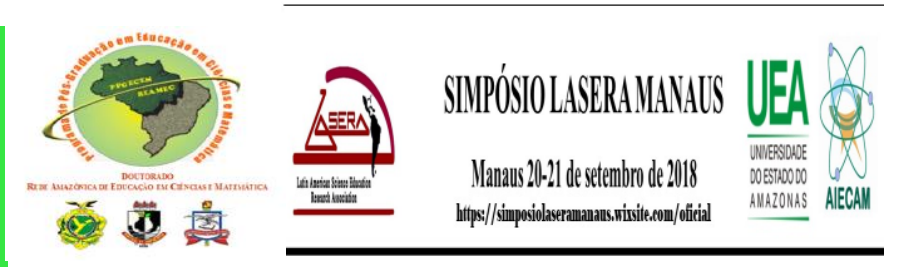

\section{0 professor e 0 ensino de Ciências}

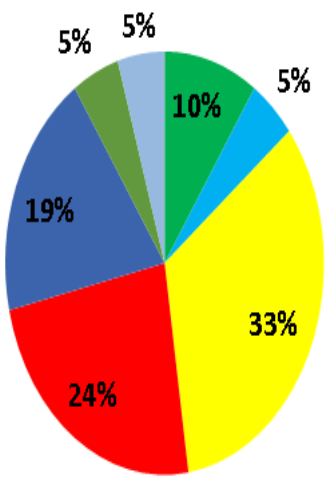

- Aulas Práticas

- Não Lembro

Ensinavam os Conteúdos

- Tradicional

- Livrescos

- Despertava Curiosidades

Outros

Fonte: Rodrigues (2018)

De forma abrangente, a observação dos dados apresentados sobre a formação do professor revela quanto ao "ensino de Ciências onde o uso das novas tecnologias da informação como recurso didático é praticamente simbólico" (CACHAPUZ, 2004, 379), relevando uma didática limitada a livros e centrado no professor. Os aspectos levantados trazem os registros dos acadêmicos com percentual que o professor ensinava: $33 \%$ somente ensinavam conteúdos no quadro; $24 \%$ tinham uma postura extremamente tradicional; $19 \%$ desenvolviam eram adeptos ao uso do livro didático; $10 \%$ ministravam aulas práticas que dinamizavam suas aulas e; $5 \%$ despertavam a curiosidade/não lembram/outros mensuravam os alunos de acordo com suas experiências em algum momento de sua trajetória escolar.

\subsection{Instrumentalização do ensino de Ciências}

Para os acadêmicos consultados no ensino de Ciências é promovido um papel essencial na formação do cidadão, onde percorre caminhos para compreender a importância e necessidade de se relação com a Natureza e os outros Homens (48\%); tem a base na saúde, estudar Ciências é adquirir conhecimentos úteis para percepção do próprio corpo e seu estado de saúde (14\%); unificação de práticas que proporcione uma aprendizagem significativa (10\%) e; outros que não houve possibilidade de identificação, como consta no gráfico 04: 


\section{REVISTA REAMEC}

Revista ta Rede Amazônica de Edurecrâa

em Ciênnizs e Matemática
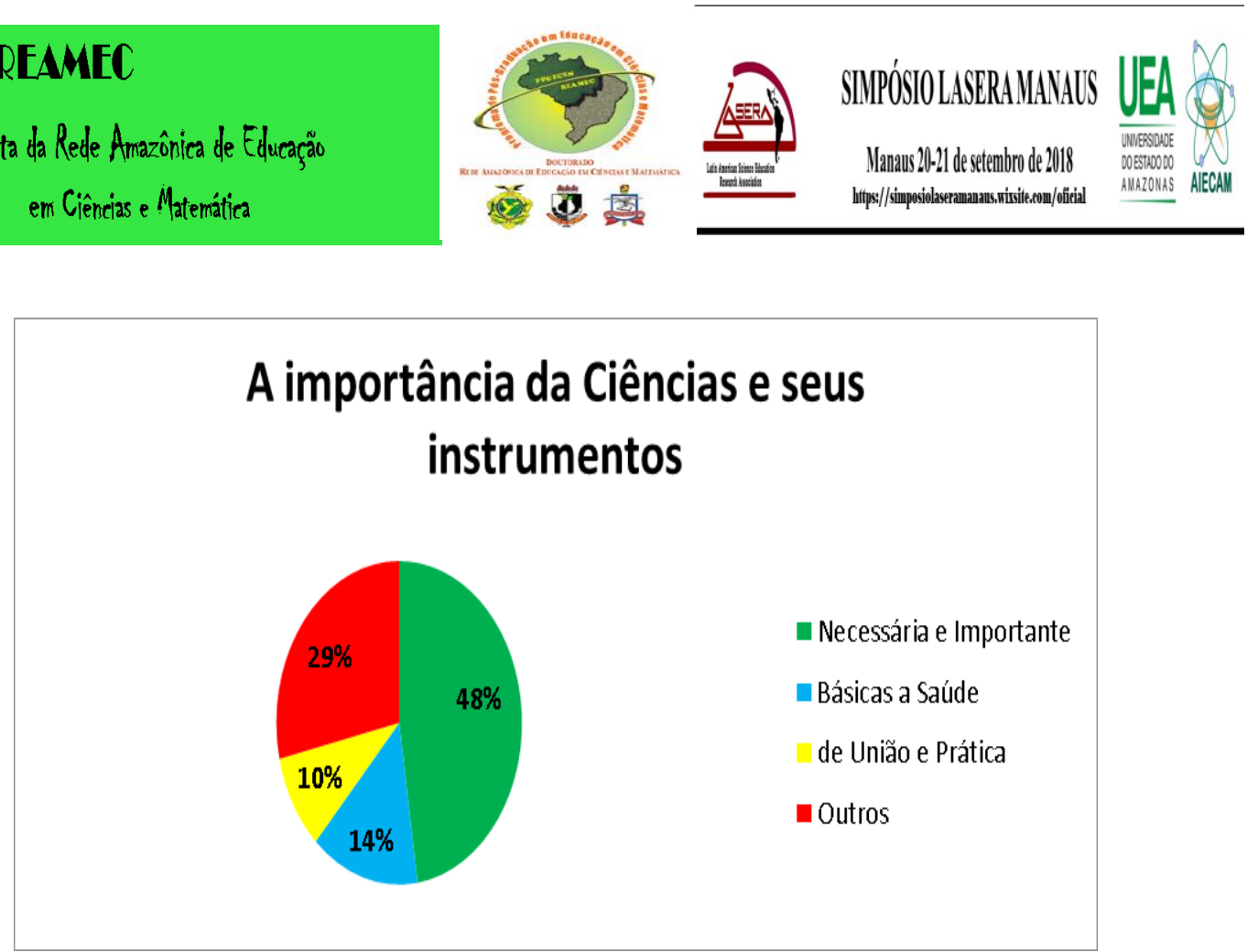

Fonte: Rodrigues (2018)

Muito mais do que a estimulação e desenvolvimento da aprendizagem de conceitos científicos exige do professor adoção de metodologias aliadas à estratégias pedagógicas e utilização de recursos didáticos que promovam dinamismo das práticas educativas. Esta constatação nos valemos de Ward at all (p. 185, 2010):

O uso de uma variedade de abordagens organizacionais no ensino de Ciências é a maneira mais efetiva de manter o interesse e de promover aprendizagem. Começar com algumas aulas com um formato com toda turma, em que as ideias dos alunos sejam evocadas e anotadas no quadro, à medida que aparecem, é bastante efetivo. Isso pode ser seguido por atividades práticas em grupo, voltadas para coletar evidências, seguidas então por uma discussão com o grupo para avaliar as ideias originais.

Nem sempre a experiência em laboratório é suficiente do aluno adquirir a aprendizagem de determinado conteúdo. Isso requer do professor procurar outras formas para dinamizar suas aulas e torna suas aulas mais interessantes, fazer uso de instrumentos e recursos que possam suprir as necessidades educativas no campo científico.

\subsection{Como o aluno (acadêmico) vê a Ciências}




\section{REVISTA REAMEC}

Revista ta Rete Amazônica de Edureç̧⿸丆口 em Ciênnias e Matemática
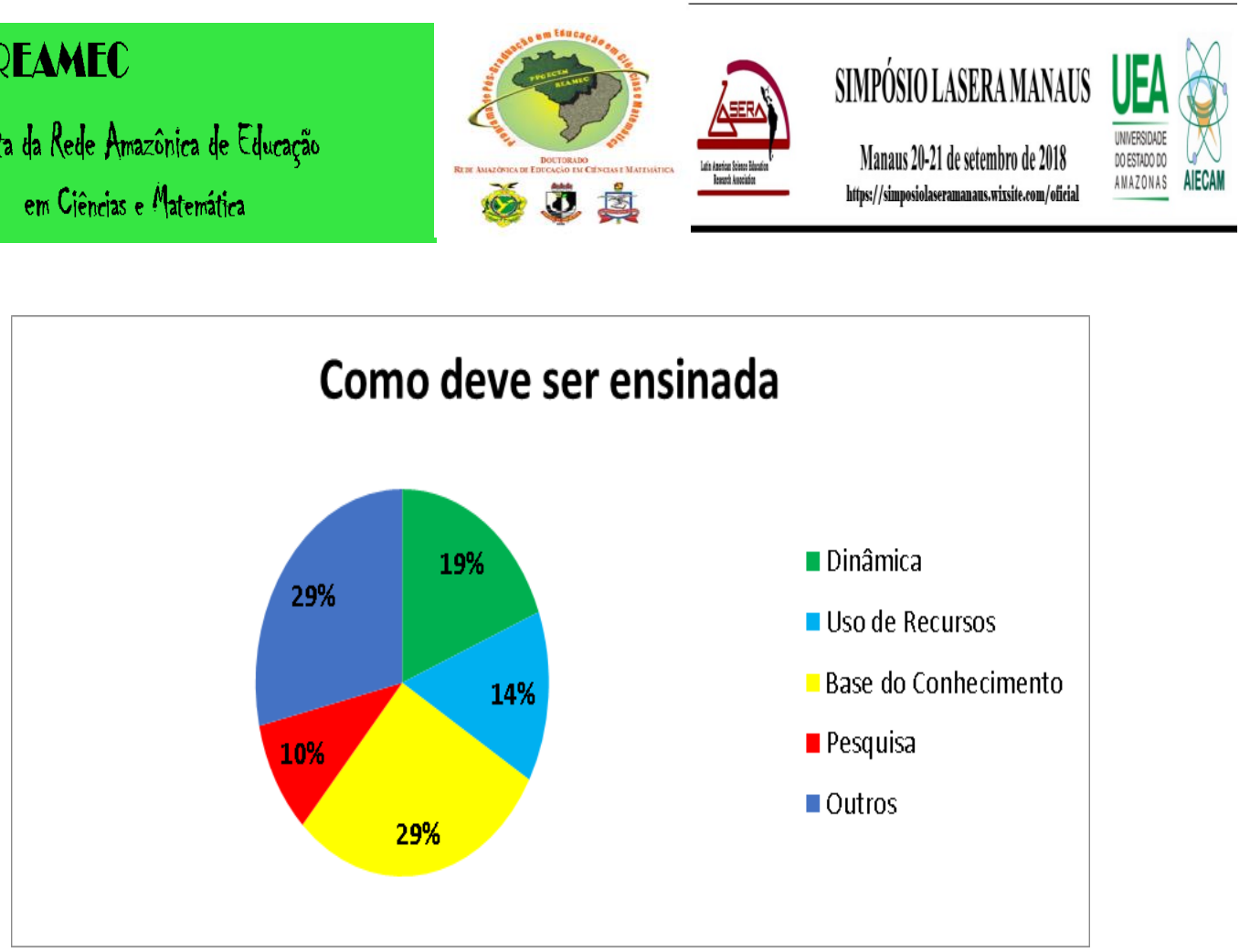

Fonte: Rodrigues (2018)

No gráfico 05, os sujeitos participantes da pesquisa demonstraram suas opiniões de como deve ensinado Ciências na escola, sendo sugeridas: trabalhar os conteúdos a partir do conhecimento que o aluno já tem (29\%); estratégias diversificadas (29\%); com a utilização de dinâmicas para tornar as aulas mais atrativas (19\%); uso de recursos didáticos pelo professor (14\%) e; incentivo do desenvolvimento da pesquisa (10\%).

\subsection{Experiências do ensino de Ciências}

\section{Experiências do ensino de Ciências}

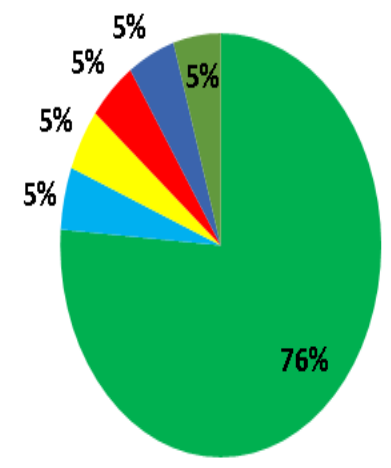

- Integrar teoria e prática

- Fixar o Aprendizado

Pesquisas

- Processo de Atendimento

- Metodologias

- Discurssão

Fonte: Rodrigues (2018)

Revista REAMEC, Cuiabá - MT, V. 6, n. Especial, dez 2018, ISSN: 2318-6674

Revista do Programa de Doutorado da Rede Amazônica de Educação em Ciências e Matemática

http://periodicoscientificos.ufmt.br/ojs/index.php/reamec 


\section{REVISTA REAMEC}

Revista ta Rete Amazônica de Edurecrąio

em Ciências e Matemática
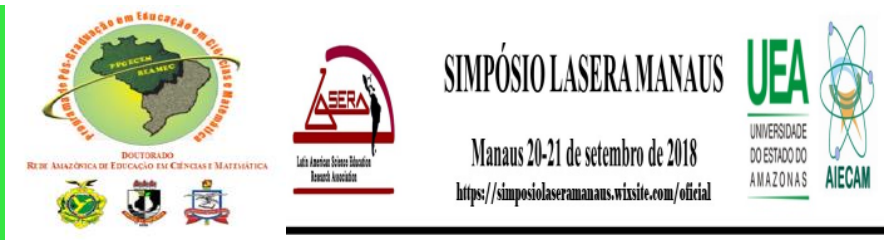

Ao considerar as experiências dos acadêmicos no ensino de Ciências disposta no gráfico 06, obtivemos dados interessantes que denotam apropriação de conhecimentos que vislumbrem novas possibilidades do trabalho docente. É interessante que um percentual de $76 \%$ dos envolvidos na pesquisa entendem ser fundamental a integração entre teoria e prática; outros 5\% apontam outras maneiras de envolver-se com o ensino de Ciências após formação para atuação no mercado de trabalho, quais sejam elas: incentivar a discussão de temáticas entre os alunos, usar diferentes metodologias, desenvolver pesquisas, promover o exercício de fixação do aprendizado através do debate coletivo e atendimento individualizado para suprir as necessidades educativas.

Nesses aspectos, é indispensável adotar procedimentos que potencializem o conhecimento científico além do senso comum, pois o conhecimento é dinâmico e nunca é resultado acabado. O professor precisa de estratégias que dialoguem com o desenvolvimento de um conhecimento crítico capaz de romper com os modelos postos. Nesse sentido, Demo (2010), enfatiza que:

O desafio da educação científica é transformar os alunos em pesquisadores durante seu processo formativo, familiarizando-os com o mundo científico. Dessa forma, possibilita-se a junção dos princípios educativo e científico que envolvem pesquisa.

Desta forma, o desenvolvimento no aluno o hábito da pesquisa requer um exercício permanente da busca, da exploração, da constante descoberta, diante de todo percurso da atuação docente, pelo exemplo. O professor é um referencial ao aluno, portanto, suas práticas devem corroborar com a construção do conhecimento científico

\section{CONCLUSÃO}

A pesquisa é um processo coletivo, sendo indispensável a abertura para o diálogo, por isso, não podemos simplificar o que é complexo, o conhecimento está sempre em construção e as universidades precisam preparar os acadêmicos para o ensino de Ciências e demais áreas, com uma proposta de contextualização da teoria com a prática.

Não há definições concretas, mas entende-se que as respostas vão se construindo durante o processo de estudo. Esta proposta se sustenta nos argumentos de Silva (2010, p. 62) 


\section{REVISTA REAMEC}

Revista da Rede Amazônica de Edureação

em Ciências e Matemática
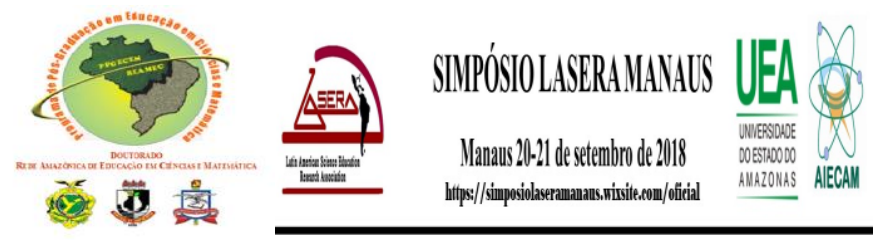

ao afirmar que o "processo de formação é marcado por pressões e conflitos". Portanto, o período de envolvimento com o acompanhamento dos acadêmicos do curso de Pedagogia nos possibilitou refletir sobre o conhecimento adquirido no período da investigação e, aos poucos, tomar consciência da necessidade de ressignificação do que se construiu como pesquisador no percurso investigativo. Dessa reflexão é interessante registrar a constante busca de superação do que afirma Bourdieu (apud SILVIA, 2010, p. 07) que "o homo academicus gosta do acabado”.

Por fim, concluímos que, o processo de transformação da realidade educacional começa prioritariamente, na perspectiva de que ela pode acontecer e o ponto de partida é a formação de professores. Além disso, as mudanças desencadeadas nesse processo se efetivam na medida em que haja a experimentação do movimento ação-reflexão-ação-reflexão. Assim, Demo (2010), propõe mudança na perspectiva no que diz respeito ao ensino de Ciências, é indispensável que os professores acreditem que a mudança é possível e possam formar uma representação coerente da inovação pretendida.

\section{REFERENCIAS}

CACHAPUZ, António; PRAIA, João; JORGE, Manuela. Da educação em ciência. Série Ciência \& Educação, v. 10, p. 363-381, 2004.

DEMO, Pedro. Educação e Alfabetização Científica. 1ª ed. Campinas, SP: Papirus, 2010.

GIL, Antonio Carlos. Como elaborar projetos de pesquisa. 4ª ed. São Paulo: Atlas, 2002.

LAKATOS, E. M. \& MARCONI, M. A. Metodologia do trabalho científico. $7^{a}$ ed. São Paulo: Atlas, 2007.

LUCKESI, C. (2013). Avaliação da aprendizagem, institucional e de larga escala. Disponível em http//:luckesi.blog.terra.com.br/acesso em 08/12/2017.

SANTOS, César Sátiro dos. Ensino de Ciências: abordagem histórico-crítica. $1^{\mathrm{a}}$ ed. Campinas-SP: Armazém do Ipê, 2012.

SILVA, Marilda da (orgs.). Pesquisa em educação: métodos e modos de fazer. São Paulo: Cultura Acadêmica, 2010.

WARD, Hellen et al. Ensino de Ciências. 2a ed. Porto Alegre: Artmed, 2010. 